
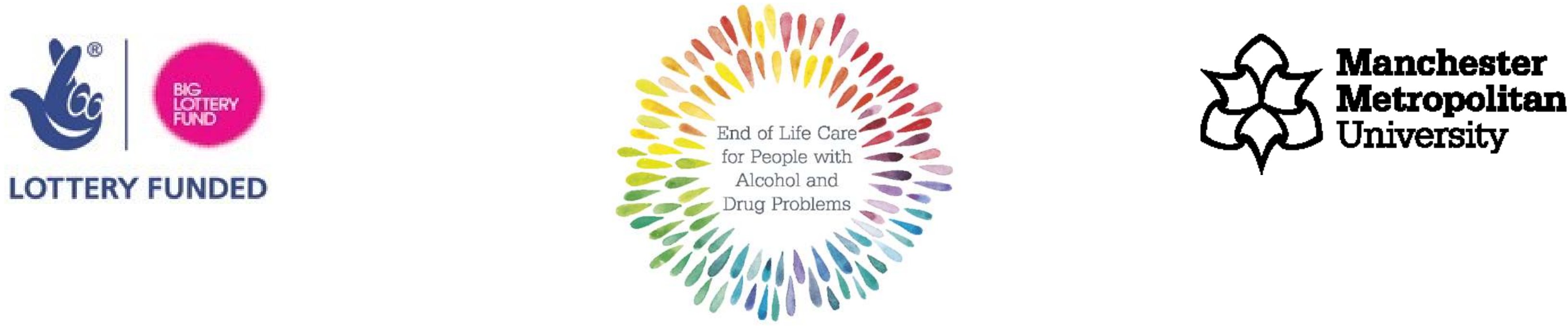

LOTTERY FUNDED

\title{
Delivering Palliative and End of Life Care to People with Alcohol and Drug Problems: Challenges and Opportunities
}

\author{
Professor Sarah Galvani, Dr Cherilyn Dance, Dr Sam Wright \\ Department of Sociology, Manchester Metropolitan University
}
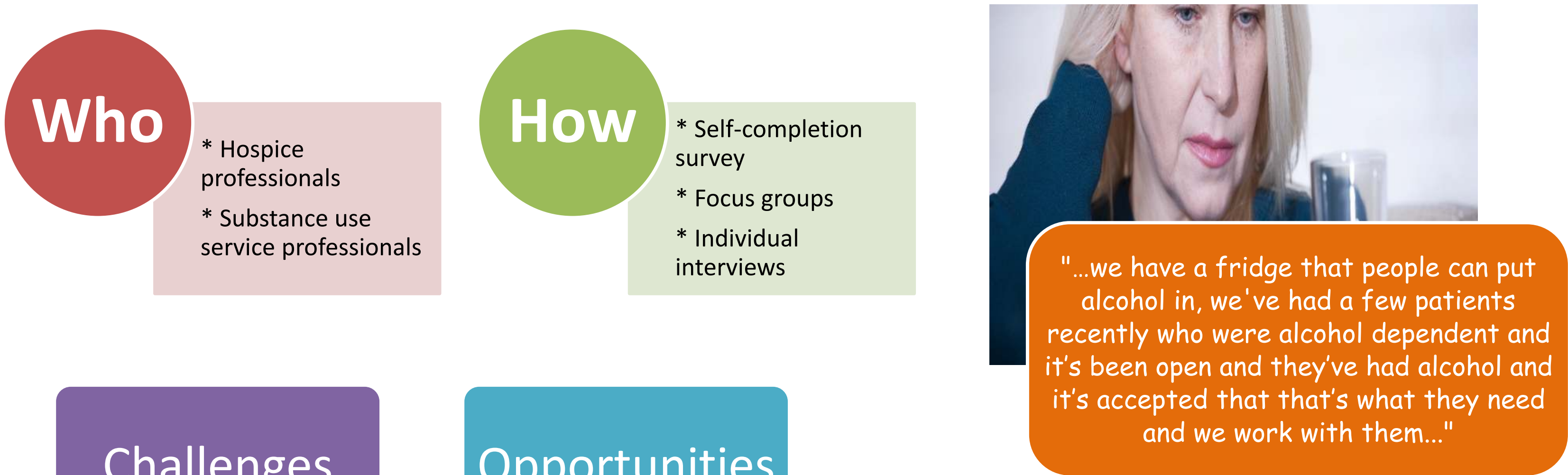

\section{Challenges}
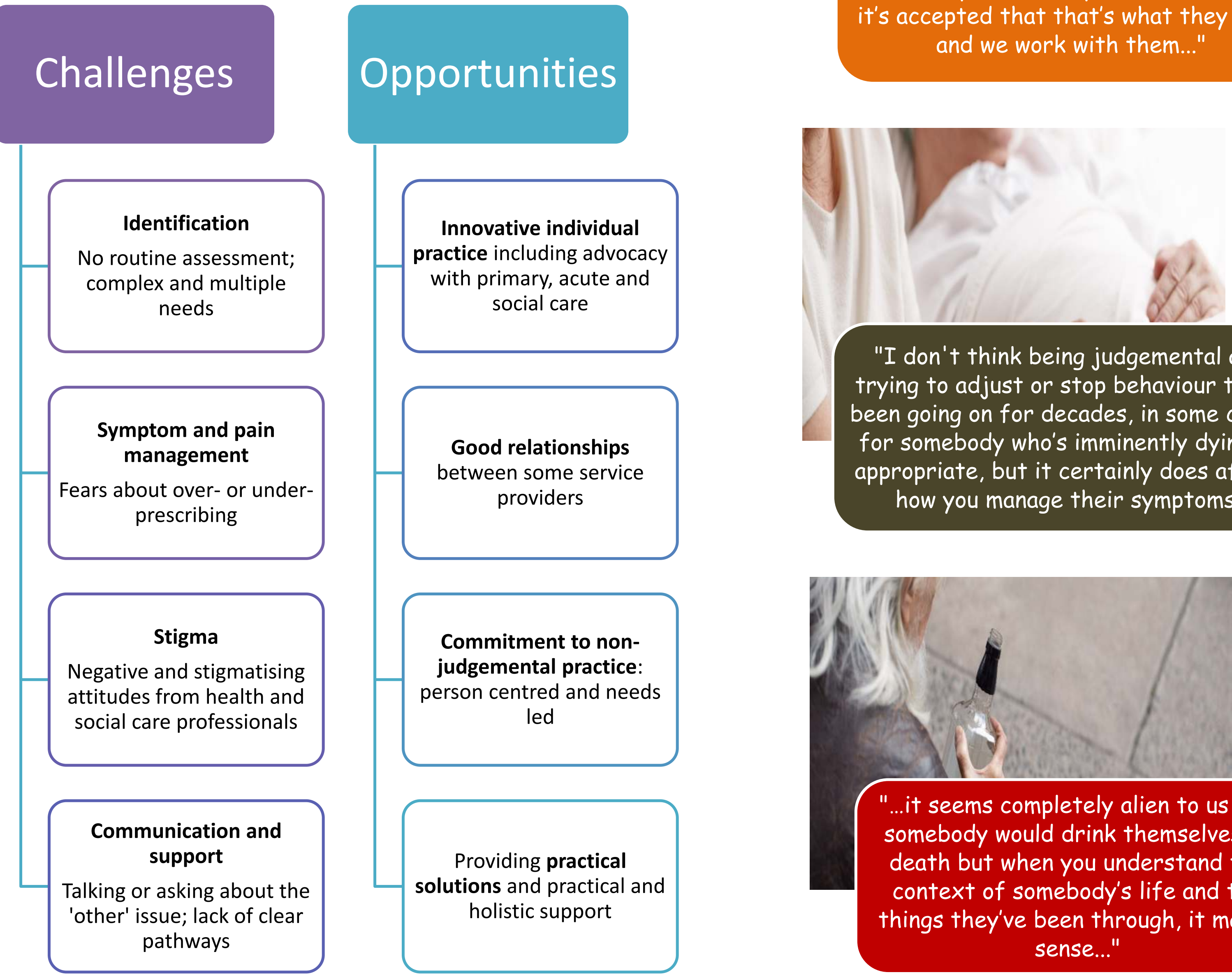

"I don't think being judgemental and trying to adjust or stop behaviour that's been going on for decades, in some cases for somebody who's imminently dying, is appropriate, but it certainly does affect how you manage their symptoms"

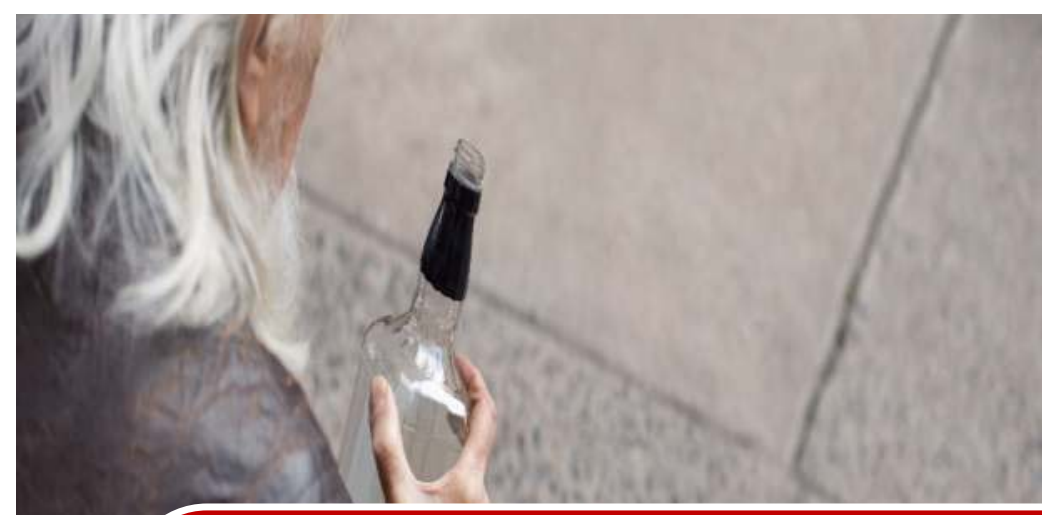

"...it seems completely alien to us why somebody would drink themselves to death but when you understand the context of somebody's life and the things they've been through, it makes sense..."

Further information from s.galvani@mmu.ac.uk or sam.wright@mmu.ac.uk. Online research reports \& digital resources: www.endoflifesubstanceuse.com 